\title{
Everolimus - a new approach in the treatment of renal cell carcinoma
}

\author{
This article was published in the following Dove Press journal: \\ Cancer Management and Research \\ 5 March 2010 \\ Number of times this article has been viewed
}

\section{G Anandappa \\ AE Hollingdale \\ TG Eisen \\ Department of Oncology, Cambridge University Hospitals NHS Foundation Trust, Cambridge, UK}

\begin{abstract}
With the increasing understanding of the biology of the disease and the development of targeted therapy, there has been a paradigm shift in the treatment of clear cell metastatic renal cell carcinoma (mRCC). Traditionally patients with metastatic RCC have been treated with immunotherapy which has limited efficacy. The multikinase inhibitors sunitinib, sorafenib and pazopanib, the VEGF antibody bevacizumab in combination with interferon and the mTOR inhibitor temsirolimus have all been shown to prolong progression-free survival in phase III studies. Here we review another mTOR inhibitor, everolimus (Afinitor ${ }^{\mathbb{B}}$; Novartis, USA) which was approved in March 2009 by the US FDA for treatment of targeted-therapy refractory metastatic renal cell cancer. The phase III study of everolimus (the RECORD study) was terminated early after a significant difference in efficacy was noted in the treatment arm with everolimus (progression-free survival of 4.0 months in patients on the treatment arm vs 1.9 months in the placebo arm). The most common adverse events were stomatitis, pneumonitis, fatigue and infections. We review Phase I-III data with a particular emphasis on safety data and patient focused outcomes.
\end{abstract}

Keywords: metastatic renal cell carcinoma, targeted therapy, mTOR, everolimus

\section{Introduction to the management issues in the treatment of metastatic RCC}

Renal cell carcinoma (RCC) accounts for $2 \%$ to $3 \%$ of malignant tumors of adults. With a world-wide incidence of 200,000 cases and 102,000 deaths per year, it remains the seventh most common cancer in men and the ninth most common cancer in women. ${ }^{1}$ RCC usually presents in the sixth or seventh decade, with a male:female ratio of 1.6:1.2 Risk factors include von Hippel-Lindau syndrome, autosomal dominant polycystic kidney disease, renal dialysis or transplant, obesity and smoking. ${ }^{3}$ Patients can present with a wide variety of symptoms; the classical triad of loin pain, painless hematuria and a mass in the flank, paraneoplastic phenomena such as fever, anorexia or symptoms of hypercalcemia, or as an incidental finding due to the increased use of imaging technologies. At presentation, disease is localized in almost $60 \%$ of patients, with locally advanced disease in $18 \%$ and metastatic disease in $19 \%$ of cases. ${ }^{4}$ The most common site for metastasis is to the lungs $(75 \%)$; other sites include soft tissue $(36 \%)$, bone $(20 \%)$, liver (18\%) and brain (8\%). ${ }^{5}$ Of the patients who present with localized disease a further third of these will go on to develop metastases in the future.

Surgery remains the main stay of treatment for non-metastatic disease; with options of partial nephrectomy, and radical nephrectomy for large tumors. Systemic therapy is the mainstay of treatment for patients with metastatic disease. Aldesleukin
Correspondence:T Eisen

Box 193 (R4), Addenbrooke's Hospital, Cambridge CB2 0QQ, UK

Tel $+44(0)$ I 223769312

$\mathrm{Fax}+44(0) 1223769313$

Email tim.eisen@medschl.cam.ac.uk 
(recombinant interleukin-2) and interferon-alfa have been the standard of care for patients with metastatic renal cell carcinoma until recently. Despite the use of these agents for more than 20 years, the effectiveness of these two drugs is still controversial. The greatest benefit is achieved when applied to a very select group of patients with good prognosis, potentially achieving durable remissions, albeit in a small minority of patients. ${ }^{6}$

Identification of the causative biological pathways and development of targeted therapy has been crucial in causing a paradigm shift in the treatment of metastatic clear cell renal cell carcinoma. Clear cell is the commonest variant accounting for $75 \%$ of renal cell carcinomas. Other variants include nonclear cell types such as papillary (10\% to $15 \%)$, chromophobe and sarcomatoid. The pathogenesis of clear cell RCC is associated with loss of function of von Hippel-Lindau (VHL) gene and overproduction of the hypoxia-inducible factor (HIF). The VHL gene is mutated in $\approx 70 \%$ of patients with RCC; additionally, VHL is silenced in another $20 \%$ of patients. $^{7}$

Loss of VHL gene product (pVHL) upregulates HIF- $\alpha$ expression which has been strongly implicated in RCC. HIF- $\alpha$ dimerizes with HIF- $\beta$ and results in the transcription of genes that regulate angiogenesis such as vascular endothelial growth factor (VEGF), platelet-derived growth factor (PDGF) and transforming growth factor beta (TGF $\beta){ }^{8,9}$ VEGF and other factors induced by HIF- $\alpha$ are thought to be the key drivers of tumor angiogenesis, permitting the growth and progression of renal cancers. ${ }^{10,11}$ Activation of mTOR (mammalian target of rapamycin) also leads to increased expression of HIF-1 $\alpha$ in clear cell renal cell cancer. ${ }^{12,13}$ VEGFR/PDGFR inhibiting drugs and the mTOR-inhibiting drugs are now the targeted therapies approved for use in clinical practice.

\section{The $m$ TOR pathway}

Activation of mTOR promotes the proliferation and survival of tumor cells. The mTOR kinase also controls angiogenic pathways via hypoxia-inducible factor- $1 \alpha$ (HIF-1 $\alpha)$, vascular endothelial growth factor (VEGF) and via endothelial and smooth muscle cell proliferation which have been implicated in the etiology of clear cell renal cell carcinoma. ${ }^{14,15}$

Rapalogs have long been known to inhibit the mTOR pathway. The natural product rapamycin binds to an intracellular protein known as FK506-binding protein 12 (FKBP12) and the resultant protein-drug complex inhibits the kinase activity of mTOR.${ }^{16} \mathrm{mTOR}$ is a highly conserved intracellular multi functional signal transduction serine-threonine kinase, and is a key regulatory protein in cancer that recognizes stress signals (eg, nutrient and energy depletion, oxidative or hypoxic stress, and proliferative and survival signals) via the phosphotidylinositol 3 kinase-protein kinase (PI3K-AKT) pathway. The PI3K-AKT-mTOR pathway is dys-regulated in many cancers. ${ }^{16}$ In response to extracellular stimuli, PI3K phosphorylates the 3'-hydroxyl of phosphotidylinositol-4, 5-bisphosphate (PIP2) to generate phosphotidylinositol-3, 4, 5-triphosphate (PIP3). The formation of PIP3 leads to membrane localization and activation of phosphotidylinositoldependent kinase-1 (PDK1) and AKT. ${ }^{17}$ The tumor suppressor phosphatase PTEN (phosphatase tensin homologue deleted on chromosome 10) dephosphorylates PIP3 reversing the action of PI3K. Activated AKT phosphorylates and inhibits tuberous sclerosis complex (TSC) and removes its inhibitory effect on mTOR. ${ }^{18,19}$

mTOR exists in two complexes called mTOR complex 1 (mTORC1) and mTOR complex 2 (mTORC2), that differ in subunit composition and sensitivity to rapamycin. ${ }^{20} \mathrm{mTORC} 1$ is highly sensitive to rapamycin whereas mTORC2 is relatively insensitive to rapamycin. ${ }^{21} \mathrm{HIF}-1 \alpha$ expression depends on mTORC1 and mTORC2 expression whilst HIF-2 $\alpha$ depends on mTORC2. ${ }^{22}$

The mechanism of action of the mTOR inhibitors is quite distinct from those of drugs inhibiting VEGFR/PDGFR. Their unique action is attributed to their effect directly on the tumor cells themselves, in part due to HIF downregulation, and on tumor endothelial cells by blocking proliferation and survival signals downstream of the VEGF receptor. ${ }^{23-25}$ One study has also shown that the benefits of mTOR inhibition may be greater in papillary renal carcinoma than in clear cell carcinoma; papillary subtype accounting for $10 \%$ to $15 \%$ of renal cell cancers. ${ }^{26}$ This is postulated to be due to HIF upregulation which is noted in patients with papillary renal cell carcinoma associated with fumarate-hydratase mutations. $^{27}$

\section{mTOR-inhibiting drugs in renal cancer}

Temsirolimus (Torisel ${ }^{\circledR}$; Wyeth, USA), was the first mTOR inhibitor to be approved for treatment of RCC. A randomized phase III trial done in patients with metastatic carcinoma and three or more of the following adverse risk features: Karnofsky performance status less than $80 \%$, lactate dehydrogenase greater than 1.5-fold laboratory upper limit of normal, hemoglobin less than laboratory lower limit of normal, corrected serum calcium concentration greater than $2.5 \mathrm{mmol} / \mathrm{L}$, time from diagnosis of renal cell carcinoma to start of treatment of less than 1 year and at least 3 metastatic sites. ${ }^{28,29}$ A total 


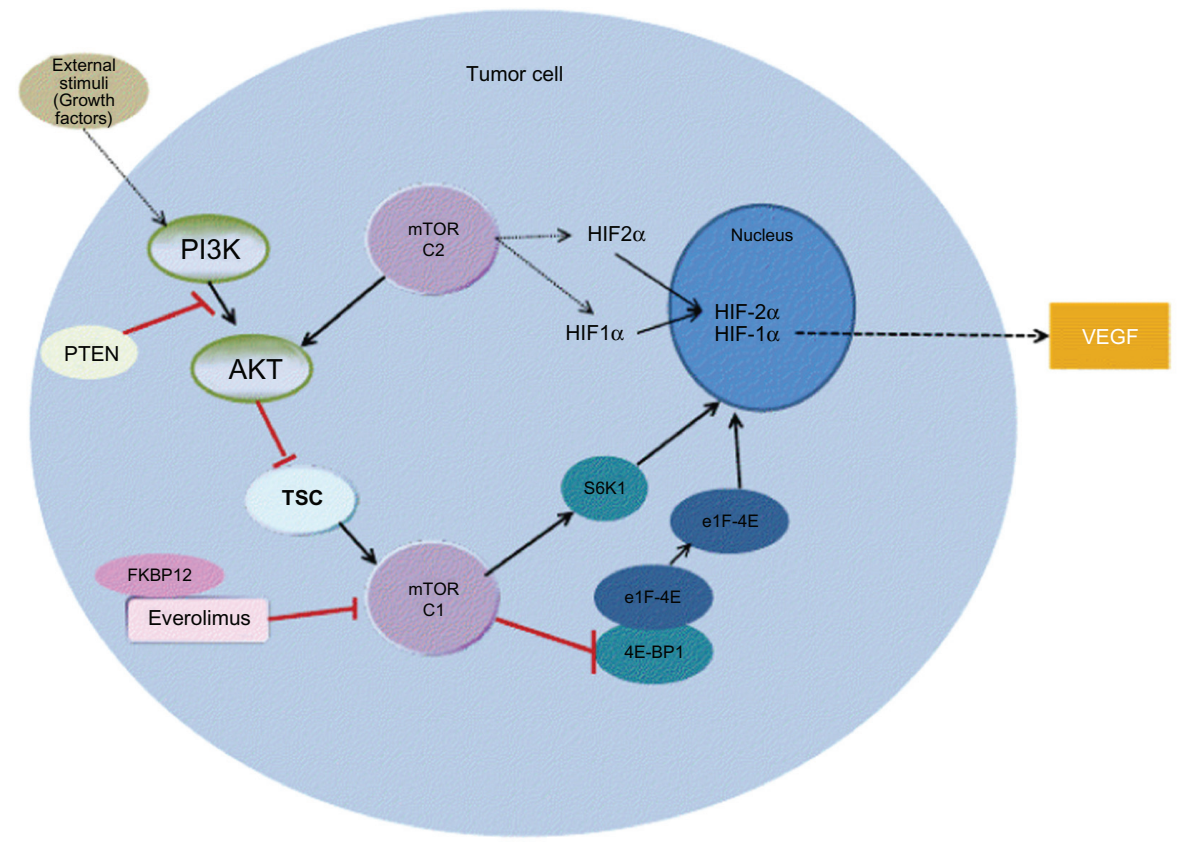

Figure I The mTOR pathway.

Abbreviations: PI3K, Phophotidyl inositol 3 kinase; PTEN, phosphotase tensin homologue; TSC, tuberous sclerosis complex; mTOR, mamalian target of rapamycin; FKBPFK506, binding protein; elF-4E, eukaryotic translation initiation factor; 4E-BP, eukaryotic elongation factor 4E-binding protein; S6K-S, 6 kinase; HIF, hypoxia inducible factor; VEGF, vascular endothelial growth factor.

of 626 patients were randomly assigned to temsirolimus $25 \mathrm{mg}$ per week intravenously versus interferon alone versus temsirolimus $15 \mathrm{mg}$ per week intravenously plus interferon. Approximately $80 \%$ of the patients in each group had a Karnofsky performance score of 60 or 70 . Clear cell carcinoma was the histology of the tumor in approximately $80 \%$ of the patients, two-thirds of the patients had prior nephrectomy and approximately $80 \%$ had received a diagnosis of metastatic disease within 12 months before enrolment. Patients with advanced renal cell carcinoma and a poor prognosis treated with temsirolimus had a longer overall survival than those on interferon monotherapy (10.9 months vs 7.3 months, hazard ratio for death $0.73,95 \%$ confidence interval [CI] 0.58 to $0.92 ; P=0.008)$. A benefit in progression-free survival (PFS) was noted for patients treated with temsirolimus alone versus interferon (median 3.8 months vs 1.9 months; $P<0.0001$ ). No survival advantage occurred in the combination treatment arm compared with interferon alone. Exploratory subgroup analysis of the effects of temsirolimus alone on overall survival was consistent across prespecified factors with the exception of age and serum lactate dehydrogenase levels. The study also revealed that the benefit of mTOR inhibition might be greater in papillary renal carcinoma than in clear cell carcinoma. ${ }^{17}$

Everolimus (Afinitor ${ }^{\circledR}$; RAD001; Novartis, USA) is an orally bioavailable mTOR inhibitor that binds with high affinity to its intracellular receptor FKBP12, at the same point in the mTOR pathway as temosirolimus. The everolimus-FKBP12 complex binds to mTOR and reduces the activity of the downstream effectors S6 ribosomal protein kinase (S6K1) and translational repressor protein eukaryotic elongation factor 4E-binding protein (4EBP). ${ }^{19}$ eIF-4F activation results in the translation of a subset of capped mRNA containing highly structured $5^{\prime}$-untranslated regions and encoding proteins involved in $\mathrm{G}_{1}$ - to S-phase progression. ${ }^{30}$ Mitogen-induced activation of the S6K1 is dependent on mTOR function and has been implicated in the translational regulation of mRNAs possessing a $5^{\prime}$-terminal oligopyrimidine tract. ${ }^{31} 5^{\prime}$-terminal oligopyrimidine tract mRNAs are characterized by a stretch of 4 to 14 pyrimidines located at their extreme $5^{\prime}$ terminus and typically encode ribosomal proteins as well as components of the translational machinery. Activation of S6K1 itself is also tightly regulated by hierarchical phosphorylation events, which are dependent on the activation of various signal transduction pathways and culminate in the phosphorylation of the rapamycin-sensitive site Thr389..$^{32,33}$ Hence, reductions in S6 phosphorylation by everolimus is expected to parallel S6K1 inactivation. Preclinical ex-vivo experiments have demonstrated that peripheral blood mononuclear cell (PBMC)-derived 4E-BP1 was unaffected by a suboptimal RAD001 dose despite transient effects on S6K1 activity, suggesting that S6K1 is a more sensitive 
marker of everolimus exposure in PBMCs than 4E-BP1. All doses of RAD001 evaluated elicited a dramatic inhibition of PBMC-derived S6K1 after 24 hours and increasing RAD001 concentrations led to almost complete inactivation of S6K1. The rate at which $\mathrm{S} 6 \mathrm{~K} 1$ activity subsequently recovered differed, with everolimus doses that were efficacious with weekly schedules causing more profound long-term effects on S6K1 activity ( $\geq 7$ days). Unlike 4E-BP1 phosphorylation, S6K1 activity can be measured in human PBMCs making it a good pharmacodynamic biomarker of everolimus activity. ${ }^{34}$

\section{Clinical studies}

\section{Phase I studies}

A 2-part dose escalation study in advanced cancer patients was conducted administering oral everolimus 5 to $30 \mathrm{mg} /$ week during part 1, with pharmacokinetic (PK) and pharmacodynamic (PD) studies. The patients had advanced solid tumours refractory to standard therapy, World Health Organization performance status of 0,1 or 2 , an estimated life expectancy of at least 3 months, adequate bone marrow function, and normal liver and renal function. During part 2 of the study, 50 and $70 \mathrm{mg}$ weekly and daily dosing of 5 and $10 \mathrm{mg}$ was administered. In part 1 of the study toxicity, antitumor activity, PK, and the relationship of dose to inhibition of S6K1 in PBMCs were evaluated with weekly oral everolimus doses of 5, 10, 20 and $30 \mathrm{mg}$. Part 1 lasted for 4 weeks, with a drug-free week in week 5. PK and PD sampling was performed pre dose for the first 4 weeks, and in week 5 . Part 2 of the study investigated higher weekly doses (50 and $70 \mathrm{mg}$ ) and daily administration (5 and $10 \mathrm{mg}$ ) for evaluation of safety data at higher weekly levels. ${ }^{35}$ The end points of the study were weekly assessments for toxicity and standard laboratory panels for 5 weeks and then monthly, and imaging assessed by RECIST criteria every 2 months. 92 patients with advanced solid tumours, including 10 renal cell carcinoma patients were part of the study. In total 18 were treated weekly in part 1, and in part 2, 37 were treated weekly, and 37 were treated daily.

\section{Safety data}

The majority of serious toxicities (18/19 of grade 3 or 4$)$ were seen at higher doses of everolimus (10 $\mathrm{mg}$ daily or $70 \mathrm{mg}$ weekly). No information about correlation of toxicity to blood levels or surrogate markers of everolimus activity in individual patients was included in the paper, although appeared to occur if the weekly area under the curve (AUC) is around $3500 \mathrm{ng} . \mathrm{h} / \mathrm{mL}$, corresponding to the higher weekly and daily dosage regimes. Dose-limiting toxicities (CTC V2.0 grade 3 or higher) at $70 \mathrm{mg}$ weekly included stomatitis ( 2 at 10mg daily), hyperglycemia (2 at $10 \mathrm{mg}$ daily and 1 at $70 \mathrm{mg}$ weekly), fatigue (1 at $70 \mathrm{mg}$ weekly), dyspnea (1 at $10 \mathrm{mg}$ daily), pneumonia (10 mg weekly), thrombocytopenia (2 at $10 \mathrm{mg}$ daily, 1 at $70 \mathrm{mg}$ weekly), hypertriglyceridemia ( 1 at $70 \mathrm{mg}$ weekly, 1 at $10 \mathrm{mg}$ daily), anorexia (2 at $10 \mathrm{mg}$ daily), pneumonitis (1 at $70 \mathrm{mg}$ weekly), erythematous rash (1 at $10 \mathrm{mg}$ daily), nausea (1 at $10 \mathrm{mg}$ daily), melena (1 at $70 \mathrm{mg}$ weekly), epistaxis (1 at $10 \mathrm{mg}$ daily). Five patients had severe toxicity that was suspected to be drug related which included hemorrhagic gastritis, recurrent epistaxis, bronchiolitis obliterans organizing pneumonia, pneumonia associated with lymphopenia and fatigue with stomatitis. ${ }^{35}$

\section{Pharmacokinetics}

\section{Absorption}

In patients with advanced solid tumors, peak steady state concentrations $\left(\mathrm{C}_{\max }\right)$ are achieved at a median time of 1 hour after daily administration of $5 \mathrm{mg}$ and $10 \mathrm{mg}$ doses under fasting conditions. In healthy subjects high-fat meals reduced systemic exposure to everolimus $10 \mathrm{mg}$ (as measured by AUC) by $22 \%$ and light fat meals reduced AUC by $32 \% .{ }^{36}$

\section{Metabolism}

Everolimus is extensively metabolized by CYP3A4 and PgP. Samples were assessable for full 24-hour PK profiles in 26 of the 31 patients who received the weekly regimen and in 10 of the daily regimen patients.

Using the weekly regimen, stable predose serum trough concentration levels from weeks 2 to 5 indicated minimal accumulation at all weekly dose levels, with steady-state achieved by week 2 of treatment. Dose normalization showed that serum steady state concentration increased in a roughly dose-proportional manner from 5 to $20 \mathrm{mg}$ per week but increased less than proportionally at higher doses. The increase in AUC at steady state was dose proportional over the full dose range. Elimination half-life averaged $30 \pm$ 8 hours across all patients and was similar to that in healthy controls.

Daily regimen usage resulted in a steady state level within a week. Trough levels were stable thereafter, averaging $5.4 \mathrm{ng} / \mathrm{mL}$ (5 mg/day dosing) and $13.2 \mathrm{ng} / \mathrm{mL}(10 \mathrm{mg} /$ day dosing). Peak concentrations were achieved within 1 hour of daily dosing with one exception (6 hours). Both maximum serum concentration and AUC increased in a doseproportional manner. Plasma concentrations and levels of sustained S6K1 inhibition observed at $\geq 20 \mathrm{mg}$ everolimus 
weekly and $\geq 5 \mathrm{mg}$ daily correlate with those seen in preclinical models resulting in antitumor activity.

Pharmacokinetic characteristics were consistent with those observed both in normal volunteers and in patients in the transplantation setting and with dose-proportional increases in AUC. ${ }^{35}$

\section{Elimination}

No specific excretion studies have been undertaken in cancer patients; however, data are available from the studies in transplant patients. Following administration of a single labeled everolimus in conjunction with cyclosporine, $80 \%$ of the radioactivity was recovered from the feces, whilst 5\% was excreted in the urine.

\section{Special populations}

Hepatic impairment: The average AUC of everolimus in 8 subjects with moderate hepatic impairment (Child-Pugh class B) was twice that found in 8 subjects with normal hepatic function. AUC correlated positively with serum bilirubin concentration and prolongation of prothrombin time and negatively correlated with serum albumin concentration. The impact of severe hepatic impairment (Child-Pugh class C) on the pharmacokinetics of everolimus has not been assessed.

Renal impairment: No significant influence of creatinine clearance was detected in a population pharmacokinetic analysis of 170 patients.

Elderly patients: No significant influence of age (27 to 85 years) on oral clearance was detected in a population pharmacokinetic analysis. $^{36}$

\section{Phase I tumor pharmacodynamic study}

A Phase I study tumor pharmacodynamic study was conducted in 55 patients with advanced solid tumors. ${ }^{37}$ Patients received everolimus in cohorts of 20,50 and $70 \mathrm{mg}$ weekly or 5 and $10 \mathrm{mg}$ daily. Dose escalation was based on doselimiting toxicity (DLT) rate during the first 4-week period. Pre- and on-treatment steady-state tumor and skin biopsies were evaluated for total and phosphorylated (p) protein S6 kinase 1, eukaryotic initiation factor 4E (eIF-4E) binding protein 1(4E-BP1), eukaryotic initiation factor $4 \mathrm{G}$ (eIF-4G), AKT and Ki-67 expression. Plasma trough levels of everolimus were determined on a weekly basis before dosing during the first 4 weeks. Dose related and schedule dependent inhibition of pS6 and peIF-4G occurred almost completely at $10 \mathrm{mg} /$ day and $\geq 50 \mathrm{mg} /$ week. Also, pAKT was upregulated in $50 \%$ of untreated tumors. Clinical benefit was observed in four patients and DLT was seen in 5 patients and included stomatitis, neutropenia and hyperglycemia. The study recommended a dosage of $10 \mathrm{mg}$ per day or $50 \mathrm{mg}$ per week.

\section{Phase II studies}

In a 2-stage, single-arm, phase II trial to determine the PFS of patients with metastatic clear cell RCC who had received $\leq 1$ prior therapy and had progressive, measurable metastatic disease, everolimus was given at a dose of $10 \mathrm{mg}$ daily. Of 41 enrolled patients, 39 were treated and evaluable for safety and 37 were evaluable for response. The median PFS was 11.2 months and the median overall survival was 22.1 months. Partial responses were observed in 14\% of patients, stable disease lasting for 3 months in $\geq 73 \%$ patients and stable disease lasting $\geq 6$ months was reported in $57 \%$ of patients. ${ }^{38}$

\section{Safety data}

This study reported the adverse events shown in Table 1.

Another multicenter Phase II trial evaluated the efficacy and safety of a combination of bevacizumab $10 \mathrm{mg} / \mathrm{kg}$ every 2 weeks and everolimus $10 \mathrm{mg}$ daily in patients with metastatic RCC. Patients with metastatic or unresectable locally recurrent clear cell RCC were enrolled and divided into 2 groups: group A, no previous treatment with sorafenib or sunitinib; group B, previous treatment with sorafenib and/or sunitinib. 59 patients (30 group A, 29 group B) were enrolled into the study, 42 patients received at least 8 weeks of treatment and were re-evaluated; 6 patients were unable to be evaluated due to toxicity, rapid progression or intercurrent

Table I Laboratory abnormalities (incidence by NCI-CTCAE V3.0 grade, number in \%) ( $n=39$ pts)

\begin{tabular}{llll}
\hline Event & Grade I & Grade 2 & Grade 3 \\
\hline Elevated alkaline phosphate & 61.5 & 30.8 & 7.7 \\
Elevated alanine transaminase & 35.9 & 20.5 & 10.3 \\
Hyperglycemia & 41.0 & 10.3 & 7.7 \\
Hypercholesterolemia & 30.8 & 7.7 & 5.1 \\
Hypophosphatemia & 28.2 & 2.6 & 0 \\
Hypertriglyceridemia & 25.6 & 25.6 & 5.1 \\
Thrombocytopenia & 61.5 & 30.8 & 7.7 \\
Anemia & 30.8 & 0 & 0 \\
Nonhematologic adverse events & & \\
Anorexia & 38.5 & 0 & 0 \\
Nausea & 35.9 & 2.6 & 0 \\
Diarrhea & 23.1 & 7.7 & 0 \\
Rash & 17.9 & 7.7 & 0 \\
Stomatitis & 10.3 & 20.5 & 0 \\
Vomiting & 7.7 & 15.4 & 0 \\
Pneumonitis & 5.1 & 25.6 & 17.9 \\
\hline
\end{tabular}


illness, and 11 were too early for evaluation. $90 \%$ of patients who completed 8 weeks of treatment had objective response $(21 \%)$ or minor response/stable disease $(69 \%)$. There was a $23 \%$ partial response rate in group $\mathrm{A}$ and $11 \%$ in group $\mathrm{B}$, with $10 \%$ patients in group A and $44 \%$ in group B having stable disease. Median PFS was 9 months in group A and 6 months in group B. ${ }^{39}$

Safety data from this study reported grade 3 or 4 proteinuria occurred in $19 \%$ of patients, fatigue in $9 \%$ and stomatitis in $8 \%$ of patients. Grade 1 or 2 toxicities were common and included fatigue $(68 \%)$, skin rash/pruritis (55\%), mucositis/stomatitis (49\%), hyperlipidemia (45\%), nausea $(40 \%)$ and hypertension $(25 \%)$. The majority of side effects reversed quickly after stopping the treatment. Pneumonitis was also reversible if identified early. The group concluded that the combination of bevacizumab and everolimus is active and tolerable, with the combination working in patients previously treated with sorafenib and/or sunitinib. ${ }^{39}$

\section{Phase III studies}

The only Phase III study to date is by the RECORD-1 study group who conducted a multicenter, randomized, double-blind, placebo-controlled trial of everolimus in patients with metastatic clear cell renal carcinoma whose disease had progressed on vascular endothelial growth factor-targeted therapy. ${ }^{40}$ Patients with metastatic renal cell carcinoma who had progressed on sunitinib, sorafenib, or both, were recruited from 86 centers in Australia, Canada, Europe, Japan and the USA. 554 patients were screened of whom 410 patients were randomly assigned in a 2:1 ratio to receive everolimus $10 \mathrm{mg}$ once daily $(\mathrm{n}=272)$ or placebo $(\mathrm{n}=138)$, in conjunction with best supportive care. $193(71 \%)$ patients in the everolimus group and 109 (79\%) in the placebo group had progressed while receiving previous therapy.

\section{Efficacy data}

The primary end point was PFS, assessed by a blinded independent central review. The study was designed to be terminated after 290 events of progression. Analysis was by intention to treat. The results of the second interim analysis indicated a significant difference in efficacy between arms and the trial was thus halted early after 191 progression events had been observed (101 [37\%] events in the everolimus group, 90 [65\%] in the placebo group; hazard ratio $0.30 .95 \%$ CI 0.22 to $0.40, P<0001)$. Median PFS was 4.0 [95\% CI 3.7 to 5.5 ] vs 1.9 [1.8 to 1.9 ] months).
The study raised some important questions about the increasing difficulty in detecting improvements in overall survival in confirmatory phase III studies with the advent of ever increasingly effective second and third-line therapies, and the growing use of cross-over design.

\section{Safety data}

This study reported the adverse events shown in Table 2 .

The group reported that most adverse events noted in both arms were grade 1 or 2 . Those that occurred more frequently in the everolimus group than placebo group were stomatitis, rash, fatigue and diarrhea. Patients in the everolimus arm had higher rates of grade 3 or 4 stomatitis, infections, and noninfectious pneumonitis than did those in the placebo group. Of the 8 patients with grade 3 pneumonitis, 6 discontinued everolimus therapy. Four showed complete clinical resolution, and three showed improvement to grade 2 or less. Grade 3 or 4 lymphopenia, grade 3 hyperglycemia, grade 3 hypophosphatemia, and grade 3 hypercholesterolemia occurred more often in patients receiving everolimus than in those administered placebo. The majority of cases of hyperglycemia occurred in patients who had an abnormal fasting glucose level before taking everolimus and optimal glycemic control before starting a patient on everolimus has been recommended. ${ }^{41}$

Study drug toxicity led to treatment discontinuation for $28(10 \%)$ patients receiving everolimus (with pneumonitis, dyspnea and fatigue being the most common reasons) and for $5(4 \%)$ patients in the placebo group. 92 (34\%) patients in the everolimus group and $20(15 \%)$ in the placebo group required a dose interruption, whereas $14(5 \%)$ in the everolimus group and one $(<1 \%)$ in the placebo group had a dose reduction with no preceding interruption.

The group reported the death of $14(5 \%)$ patients in the everolimus group and $6(4 \%)$ in the placebo group within 28 days of their last dose (all causes); one patient in the everolimus group died from overwhelming candidal sepsis complicated by acute respiratory failure, which they felt might have been attributable to the study drug. One patient receiving placebo died from a myocardial infarction, with all of the remaining deaths attributed to underlying malignancy. ${ }^{40}$

\section{Everolimus and pneumonitis}

Non-infectious pneumonitis, a potentially serious adverse event associated with rapamycin and rapamycin derivative treatment is also seen with everolimus. It comprises one of a number of typical radiographic appearances with or without symptoms (dry cough, breathlessness, malaise) and signs (pleural effusion, crepitations, hypoxemia) in the absence 
Table 2 Adverse events in percentages

\begin{tabular}{|c|c|c|c|c|c|c|c|}
\hline \multirow{2}{*}{$\begin{array}{l}\text { Cohorts } \\
\text { Grades }\end{array}$} & \multicolumn{3}{|c|}{$\begin{array}{l}\text { Everolimus group } \\
(\mathrm{n}=\mathbf{2 6 9})\end{array}$} & \multicolumn{3}{|c|}{$\begin{array}{l}\text { Placebo group } \\
(n=135)\end{array}$} & \multirow{2}{*}{$\begin{array}{l}\text { Significant difference } \\
\text { between groups } \\
P \text { value }\end{array}$} \\
\hline & All grades & Grade 3 & Grade 4 & All grades & Grade 3 & Grade 4 & \\
\hline \multicolumn{8}{|l|}{ Adverse events } \\
\hline Stomatitis & 40 & 3 & 0 & 8 & 0 & 0 & 0.03 \\
\hline Rash & 25 & $<1$ & 0 & 4 & 0 & 0 & \\
\hline Fatigue & 20 & 3 & 0 & 16 & $<1$ & 0 & \\
\hline Asthenia & 18 & 1 & 0 & 8 & $<1$ & 0 & \\
\hline Diarrhea & 17 & 1 & 0 & 3 & 0 & 0 & \\
\hline Anorexia & 16 & $<1$ & 0 & 6 & 0 & 0 & \\
\hline Nausea & 15 & 0 & 0 & 8 & 0 & 0 & \\
\hline Mucosal inflammation & 14 & 1 & 0 & 2 & 0 & 0 & \\
\hline Vomiting & 12 & 0 & 0 & 4 & 0 & 0 & \\
\hline Cough & 12 & 0 & 0 & 4 & 0 & 0 & \\
\hline Dry skin & 11 & $<1$ & 0 & 4 & 0 & 0 & \\
\hline Infections & 10 & 2 & 1 & 2 & 0 & 0 & 0.03 \\
\hline Pneumonitis & 8 & 3 & 0 & 0 & 0 & 0 & \\
\hline Dyspnea & 8 & 1 & 0 & 2 & 0 & 0 & \\
\hline \multicolumn{8}{|c|}{ Laboratory abnormalities } \\
\hline Anemia & 91 & 9 & $<1$ & 76 & 5 & 0 & \\
\hline Hypercholesterolemia & 76 & 3 & 0 & 32 & 0 & 0 & 0.03 \\
\hline Hypertriglyceridemia & 71 & $<1$ & 0 & 30 & 0 & 0 & \\
\hline Hyperglycemia & 50 & 12 & 0 & 23 & I & 0 & $<0.0001$ \\
\hline Raised creatinine & 46 & $<1$ & 0 & 33 & 0 & 0 & \\
\hline Lymphopenia & 42 & 14 & 1 & 29 & 5 & 0 & 0.002 \\
\hline $\begin{array}{l}\text { Raised alkaline } \\
\text { phosphatase }\end{array}$ & 37 & $<1$ & 0 & 30 & 1 & 0 & \\
\hline Hypophospatemia & 32 & 4 & 0 & 7 & 0 & 0 & 0.01 \\
\hline Leucopenia & 26 & 0 & 0 & 8 & 0 & $<1$ & \\
\hline $\begin{array}{l}\text { Raised aspartate } \\
\text { aminotransferase }\end{array}$ & 21 & $<1$ & 0 & 7 & 0 & 0 & \\
\hline Thrombocytopenia & 20 & $<1$ & 0 & 2 & 0 & $<1$ & \\
\hline $\begin{array}{l}\text { Raised alanine } \\
\text { aminotransferase }\end{array}$ & 18 & $<1$ & 0 & 4 & 0 & 0 & \\
\hline Hypocalcemia & 17 & 0 & 0 & 6 & 0 & 0 & \\
\hline Neutropenia & 11 & 0 & 0 & 3 & 0 & 0 & \\
\hline
\end{tabular}

of a non-drug cause. ${ }^{41}$ The Phase II study discussed earlier reported grade 1 or 2 pneumonitis in $31 \%$ of patients. Grade 3 pneumonitis occurred in $19 \%$ of patients which resolved with dose delays and dose reductions. None of the patients required steroids and the pneumonitis resolved with the cessation of the drug. ${ }^{38}$ In the Phase III study, grade 3 pneumonitis was reported in $3 \%$ of the patients. The group planned on a detailed analysis of the clinical and radiological features which may provide more insight into the mechanism of causation. As with any novel therapy, the diagnosis and management of toxicity changes and develops with time and experience. This is the most likely explanation for the differences seen in pneumonitis between the Phase II and Phase III studies, as it cannot be explained in terms of different patient characteristics or previous therapy. The drug company recommendations on the management of non-infections pneumonitis (see Table 4).

\section{Patient-focused outcomes including quality of life and satisfaction}

The RECORD-1 study assessed health-related quality-oflife with the European Organization for the Research and Treatment of Cancer (EORTC) QLQ-30 and Functional assessment of cancer therapy Kidney Symptom IndexDisease related symptoms (FKSI-DRS) questionnaires. These 
Table 3 Management of noninfectious pneumonitis ${ }^{41}$

\begin{tabular}{|c|c|c|c|}
\hline Severity & Recommended investigations & Management & Everolimus dose adjustment \\
\hline $\begin{array}{l}\text { Grade I: Asymptomatic; clinical } \\
\text { or diagnostic observations only; } \\
\text { intervention not indicated }\end{array}$ & $\begin{array}{l}\text { CT scans with lung windows and } \\
\text { pulmonary function testing }{ }^{\mathrm{a}} \text { Repeat } \\
\text { a chest } \mathrm{X} \text {-ray/CT scan every } \\
2 \text { cycles until return to baseline. }\end{array}$ & $\begin{array}{l}\text { No specific therapy } \\
\text { is required }\end{array}$ & Adminster $100 \%$ of the dose \\
\hline $\begin{array}{l}\text { Grade 2: Symptomatic; medical } \\
\text { intervention indicated; limiting } \\
\text { instrumental ADL }\end{array}$ & $\begin{array}{l}\text { CT scan with lung windows } \\
\text { and pulmonary function testing } \\
\text { Repeat each subsequent cycle } \\
\text { until return to baseline. } \\
\text { Consider bronchoscopy }\end{array}$ & $\begin{array}{l}\text { Symptomatic only. } \\
\text { Corticosteroids if cough } \\
\text { is troublesome }\end{array}$ & $\begin{array}{l}\text { Reduce dose until recovery to grade } \\
\leq \text { I. Everolimus may also be interrupted } \\
\text { if symptoms are troublesome. } \\
\text { Discontinue treatment if patient fails to } \\
\text { recover to grade } \leq \text { I within } 3 \text { weeks }\end{array}$ \\
\hline $\begin{array}{l}\text { Grade 3: Severe symptoms; } \\
\text { limiting self care ADL; } \\
\text { oxygen indicated }\end{array}$ & $\begin{array}{l}\text { CT scan with lung windows } \\
\text { and pulmonary function testing. } \\
\text { Repeat each subsequent cycle } \\
\text { until return to baseline. } \\
\text { Bronchoscopy is required }\end{array}$ & $\begin{array}{l}\text { Prescribe corticosteroids } \\
\text { if infective origin is ruled } \\
\text { out. Taper as medically } \\
\text { indicated }\end{array}$ & $\begin{array}{l}\text { Hold treatment until recovery to grade } \\
\leq \mathrm{I} \text {. May restart everolimus within } \\
2 \text { weeks at a reduced dose (by one } \\
\text { level) if evidence of clinical benefit }\end{array}$ \\
\hline $\begin{array}{l}\text { Grade 4: Life-threatening } \\
\text { respiratory compromise; urgent } \\
\text { intervention indicated } \\
\text { (eg, tracheotomy or intubation }\end{array}$ & $\begin{array}{l}\text { CT scan with lung windows and } \\
\text { pulmonary function testing. } \\
\text { Repeat each subsequent cycle until } \\
\text { return to baseline. Bronchoscopy } \\
\text { is required }\end{array}$ & $\begin{array}{l}\text { Prescribe corticosteroids } \\
\text { if infective origin is ruled } \\
\text { out. Taper as medically } \\
\text { indicated }\end{array}$ & Discontinue treatment \\
\hline
\end{tabular}

aPulmonary function test includes spirometry, carbon monoxide diffusion capacity (DLCO), and room air oxygen saturation at rest.

bBronchoscopy to include biopsy and/or bronchoalveolar lavage.

Abbreviation: ADL, activities of daily living.

were administered before randomization, on the first day of each cycle, and on discontinuation from the study.

No significant differences were evident between the everolimus group and the placebo group in the time to definitive deterioration of patient-reported outcomes, as determined by pre-established criteria for clinically meaningful changes (EORTC QLQ-C30:physical functioning scale hazard ratio $0.94,95 \%$ CI 0.64 to 1.39 ; global health status/quality of life score $1.02,0.70$ to 1.50 ; FKSI-DRS risk score:0.82, 0.57 to 1.18 ). Longitudinal mean scores for the FKSI-DRS and the global health status/quality of life, physical, role functioning, emotional, cognitive and social functioning, and symptoms scales of the EORTC QLQ-C30 questionnaire indicated that quality of life was sustained during treatment with everolimus relative to placebo. This was irrespective of the adverse effects that might be expected from the toxicities associated with an active treatment. There was therefore no detrimental effect on health-related quality of life for everolimus compared with placebo in this study. ${ }^{41}$

Table 4 www.clinicaltrials.gov ${ }^{42}$

\begin{tabular}{|c|c|c|c|c|}
\hline Phase/sites & $\begin{array}{l}\text { Monotherapyl } \\
\text { combination drugs }\end{array}$ & Histological type & Outcome measures & NCT ID \\
\hline $\begin{array}{l}\text { Phase II (RECORD-3), } \\
\text { multicenter }\end{array}$ & $\begin{array}{l}\text { Everolimus followed by } \\
\text { Sunitinib vs Sunitinib } \\
\text { followed by Everolimus }\end{array}$ & All sub-types & Efficacy and safety data & NCT00903I75 \\
\hline Phase II & $\begin{array}{l}\text { Everolimus and } \\
\text { bevacizumab }\end{array}$ & $\begin{array}{l}\text { Treatment refractory } \\
\text { predominantly clear cell } \\
\text { or predominantly } \\
\text { sarcomatoid features }\end{array}$ & Progression free survival & NCT0065I482 \\
\hline $\begin{array}{l}\text { Phase I/II } \\
\text { Single group assignment }\end{array}$ & $\begin{array}{l}\text { Everolimus and } \\
\text { sorafenib }\end{array}$ & Clear cell renal cancer & $\begin{array}{l}\text { Maximum tolerated dose } \\
\text { and objective response rate }\end{array}$ & NCT00384969 \\
\hline $\begin{array}{l}\text { Phase II, multicenter } \\
\text { (RAPTOR) }\end{array}$ & Monotherapy & $\begin{array}{l}\text { Metastatic papillary } \\
\text { cell cancer }\end{array}$ & $\begin{array}{l}\text { Efficacy-defined as the } \\
\text { percentage of patients } \\
\text { progression-free at } 6 \text { months }\end{array}$ & NCT00688753 \\
\hline Phase II & Monotherapy & $\begin{array}{l}\text { Non-clear cell renal cell } \\
\text { carcinoma }\end{array}$ & Progression free survival & NCT00830895 \\
\hline
\end{tabular}




\section{Ongoing clinical trials Conclusion}

Understanding of the biology of advanced RCC and the approval of several drugs for treatment has now meant that there are logical ways of combining the many therapeutic options for this disease. There is growing evidence that administering targeted therapies sequentially provides clinical benefit by inducing tumor shrinkage and prolonged PFS. By using these drugs sequentially, one can expect to increase PFS of up to 27 months. ${ }^{43}$ Everolimus may become standard second or third line therapy in patients who have progressive disease on or after first-line therapy with multi-kinase inhibitors or VEGF inhibitors, especially given its minimal effect on patients' quality of life. Careful patient selection and monitoring of therapy, including surrogate/predictive biomarkers is essential. Although the stability of certain phosphoproteins, in particular phospho-Akt, has been called into question, phosphor-S6 appears to be a promising potential predictive biomarker for assessing response to mTOR inhibitors, which may be validated through both larger retrospective analysis and prospective studies. ${ }^{44}$

There have been recent studies suggesting that HIF-2 $\alpha$ expression, which is dependent on mTORC2 is critical in RCC tumorigenesis. This could mean that targeting rapamycin-insensitive $\mathrm{mTORC} 2$, which lies upstream of $\mathrm{AKT}^{25}$ could prove to be important in patients who develop resistance whilst on everolimus therapy. Another mechanism of resistance involves increased insulin growth factor-1 receptor (IGF-1R)/PI3K/AKT signaling as a result of loss of $\mathrm{mTOR} / \mathrm{S} 6 \mathrm{~K}$ inhibition whilst on therapy which limits the antitumor effect of mTOR inhibitors. Combined therapy with IGF-1R inhibitors or inhibitors of PI3K and AKT may therefore be useful. ${ }^{45-47}$ More studies looking into the mechanisms of resistance to these compounds need to be done as our experience with this agent increases.

\section{Disclosures}

The authors declare no conflicts of interest.

\section{References}

1. Gupta K, Miller JD, Li JZ, Russell MW, Charbonneau C. Epidemiological and socioeconomic burden of metastatic renal cell carcinoma; a literature review. Cancer Treat Rev. 2008;34:193-205.

2. Jocham D, Richter A, Hoffmann L, et al. Adjuvant autologous renal tumour cell vaccine and risk of tumour progression in patients with renal-cell carcinoma after radical nephrectomy: phase III, randomized controlled trial. Lancet. 2004;363:594-599.

3. Moyad MA. Review of potential risk factors for kidney (renal cell) cancer. Semin Urol Oncol. 2001;19(4):280-293.
4. Horner MJ, Ries LAG, Krapcho M, et al. SEER Cancer Statistics Review, 1975-2006, National Cancer Institute. Bethesda, MD, http://seer.cancer. gov/csr/1975_2006/, based on November 2008 SEER data submission, posted to the SEER web site, 2009.

5. Maldazys JD, deKernion JB. Prognostic factors in metastatic renal carcinoma. J Urol. 1986;136:376-379.

6. Rini BI, Campbell SC, Escudier B. Renal Cell Carcinoma. Lancet. 2009;373:1119-1132.

7. Banks RE, Tirukonda P, Taylor C, et al. Genetic and epigenetic analysis of von Hippel-Lindau (VHL) gene alterations and relationship with clinical variables in sporadic renal cancer. Cancer Res. 2006;66:2000-2011.

8. Semenza GL. HIF-1 and human disease: one highly involved factor. Genes Dev. 2000;14:1983-1991.

9. Hickey MM, Simon MC. Regulation of angiogenesis by hypoxia and hypoxia-inducible factors. Curr Top Dev Biol. 2006;76:217-257.

10. Gnarra JR, Tory K, Weng Y, et al. Mutations of the VHL tumor suppressor gene in renal carcinoma. Nat Gen. 1994;7:85-90.

11. Sato K, Tsuchiya N, Sasaki R, et al. Increased serum levels of vascular endothelial growth factor in patients with renal cell carcinoma. Jpn J Cancer Research. 1999;90:874-879.

12. Hudson CC, Liu M, Chiang GG, Otterness DM, et al. Regulation of hypoxia-inducible factor-1alpha expression and function by the mammalian target of rapamycin. Mol Cell Biol. 2002;22:7004-7014.

13. Robb VA, Karbowniczek M, Klien-Szanto AJ, et al. Activation of the mTOR signaling pathway in renal clear cell carcinoma. $J$ Urol. 2007; 177:346-335.

14. Corradetti MN, Guan KL. Upstream of the mammalian target of rapamycin: Do all roads pass through mTOR? Oncogene. 2006;25:6347-6360.

15. Mamane Y, Petroulakis E, LeBacquer O, et al. mTOR, translation initiation and cancer. Oncogene. 2006;25:6416-6422.

16. Faivre S, Kroemer G, Raymond E. Current development of mTOR inhibitors as anticancer agents. Nat Rev Drug Discovery. 2006;5:671-688.

17. Hay N, Sonenberg N. Upstream and downstream of mTOR. Genes Dev. 2004;18:1926-1945.

18. Kwiatkowski DJ. Rhebbing up mTOR: new insights on TSC1 and TSC 2, and the pathogenesis of tuberous sclerosis. Cancer Biol Ther. $2003 ; 2: 471-476$.

19. Inoki $\mathrm{K}, \mathrm{Li} \mathrm{Y,} \mathrm{Xu} \mathrm{T,} \mathrm{Guan} \mathrm{KL.} \mathrm{Rheb} \mathrm{GTPase} \mathrm{is} \mathrm{a} \mathrm{direct} \mathrm{target} \mathrm{of}$ TSC2 GAP activity and regulates mTOR signalling. Genes Dev. 2003;17:1829-1834.

20. Guertin DA, Sabatini DM. Defining the role of mTOR in cancer. Cancer Cell. 2007;12:9-22.

21. Sabatini DM. mTOR and cancer: insights into a complex relationship. Nat Rev Cancer. 2006;6:729-734.

22. Toschi A, Lee, E, Gadir N, et al. Differential dependence of Hypoxiainducible factors $1 \alpha$ and $2 \alpha$ on mTORC1 and mTORC2. J Biol Chem. 2008;283:34495-34499.

23. Lane HA, Wood JM, McSheehy PM, et al. mTOR inhibitor RAD001 (Everolimus) has antiangiogenic/vascular properties distinct from a VEGF tyrosine kinase inhibitor. Clin Cancer Res. 2009; 15:1612-1622.

24. Phung TL, Eyiah-Mensah G, O’Donnell RK, et al. Endothelial Akt signalling is rate-limiting for rapamycin inhibition of mouse mammary tumor progression. Cancer Res. 2007;67:5070-5075.

25. Zachary I. VEGF signalling: integration and multi-tasking in endothelial cell biology. Biochem Soc Trans. 2003;31:1171-1177.

26. Hudes G, Carducci M, Tomczak P, et al. Temsirolimus, interferon alfa, or both for advanced renal-cell carcinoma. $N$ Engl J Med. 2007;356:2271-2281.

27. Isaacs JS, Jung YJ, Mole DR, et al. HIF over expression correlates with biallelic loss of fumarate hydratase in renal cell cancer: novel role of fumarate in regulation of HIF stability. Cancer Cell. $2005 ; 8: 143-153$.

28. Motzer RJ, Mazumdar M, Bacik J, Berg W, Amsterdam A, Ferrara J. Survival and prognostic stratification of 670 patients with advanced renal cell carcinoma. J Clin Oncol. 1999;17:2530-2540. 
29. Mekhail TM, Abou-Jawde RM, Boumerhi G, et al. Validation and extension of the Memorial Sloan Kettering prognostic factors model for survival in patients with previously untreated metastatic renal cell carcinoma. J Clin Oncol. 2005;23:832-841.

30. Hashemolhosseini S, Nagamine Y, Morley SJ, et al. Rapamycin inhibition of the $\mathrm{G}_{1}$ to $\mathrm{S}$ transition is mediated by effects on cyclin D1 mRNA and protein stability. J Biol Chem. 1998;273:14424-14429.

31. Jefferies HB, Reinhard C, Kozma SC, Thomas G. Rapamycin selectively represses translation of the "polypyrimidine tract" mRNA family. Proc Natl Acad Sci U S A. 1994;91:4441-4445.

32. Pearson RB, Dennis PB, Han JW, et al. The principal target of rapamycin-induced p70s6k inactivation is a novel phosphorylation site within a conserved hydrophobic domain. EMBO J. 1995;14:5279-5287.

33. Dufner A, Thomas G. Ribosomal S6 kinase signaling and the control of translation. Exp Cell Res. 1999;253:100-109.

34. Boulay A, Zumstein-Mecker S, Stephan C, et al. Antitumor efficacy of intermittent treatment schedules with the rapamycin derivative RAD001 correlates with prolonged inactivation of ribosomal protein S6 kinase 1 in peripheral blood mononuclear cells. Cancer Res. 2004; 64:252-261.

35. O'Donnell A, Faivre S, Burris HA 3rd, et al. Phase I Pharmacokinetic and Pharmacodynamic study of the oral mammalian target of Rapamycin inhibitor Everolimus in patients with advanced solid tumours. J Clin Oncol. 2008;26:1588-1595.

36. Everolimus-Summary of Product Characteristics. Novartis Pharma AG, Basel, Switzerland.

37. Tabernero J, Rojo F, Calvo E, et al. Dose- and Schedule-dependent inhibition of mammalian target of Rapamycin pathway with Everolimus: A phase I tumour pharmacodynamic study in patients with advanced solid tumours. J Clin Oncol. 2008;26:1603-1610.
38. Amato RJ, Jac J, Giessinger S, Saxena S, Willis JP. A Phase II study with a daily regimen of the oral mTOR inhibitor RAD001(Everolimus) in patients with metastatic clear cell renal cell cancer. Cancer. 2009; 115:2438-2446.

39. Whorf RC, Hainsworth JD, Spigel DR, et al. Phase II study of bevacizumab and everolimus (RAD001) in the treatment of advanced renal cell carcinoma (RCC). J Clin Oncol. 2008;26(15S):5010.

40. Motzer RJ, Escudier B, Oudard S, et al. Efficacy of everolimus in advanced renal cell carcinoma: a double-blind, randomised, placebocontrolled phase III trial. Lancet. 2008;372:449-456.

41. A practical guide to managing adverse events with Afinitor. 2009, Novartis Pharma AG, Basel, Switzerland.

42. www.clinicaltrials.gov. Accessed October 31, 2009

43. Escudier B, Goupil MG, Massard C, et al. Sequential Therapy in Renal Cell Carcinoma. Cancer. 2009;115(10 suppl):2221-2226.

44. Atkins MB, Choueiri TK, Cho D, Regan M, Signoretti S. Treatment selection for patients with metastatic renal cell carcinoma. Cancer. 2009;115(10 Suppl):2327-2333.

45. Wan X, Harkavy B, Shen N, et al. Rapamycin induces feedback activation of Akt signaling through an IGF-1R-dependent mechanism. Oncogene. 2007;26:1932-1940.

46. O'Reilly KE, Rojo F, She Q, et al. mTOR inhibition induces upstream receptor tyrosine kinase signaling and activates Akt. Cancer Res. 2006;6:1500-1508.

47. Shi Y, Yan H, Frost P, et al. Mammalian target of rapamycininhibitors activate the AKT kinase in multiple myeloma cells by up-regulating the insulin-like growth factor receptor/insulin receptor substrate1/phosphatidylinositol 3-kinase cascade. Mol Cancer Ther. 2005; $4: 1533-1540$
Cancer Management and Research

\section{Publish your work in this journal}

Cancer Management and Research is an international, peer-reviewed open access journal focusing on cancer research and the optimal use of preventative and integrated treatment interventions to achieve improved outcomes, enhanced survival and quality of life for the cancer patient. The journal welcomes original research, clinical \& epidemiological

\section{Dovepress}

studies, reviews \& evaluations, guidelines, expert opinion \& commentary, case reports \& extended reports. The manuscript management system is completely online and includes a very quick and fair peerreview system, which is all easy to use. Visit http://www.dovepress.com/ testimonials.php to read real quotes from published authors. 